\title{
Feasibility Study for Chemical Analysis by X-ray Spectrometer Using the Fundamental Parameter Method
}

\author{
K. Sugiyama, Y. Waseda and J.W. Essel ${ }^{1}$ \\ Institute for'Advanced Materials Processing (AMP), \\ Tohoku University, Sendai 980, Japan
}

(Received January 22, 1993; final form March 1, 1993)

\begin{abstract}
Application of the fundamental parameter (FP) method was tested for obtaining quantitative $\mathrm{X}$-ray fluorescent analysis of a multi-component inorganic system. The systems selected for analysis were lowalloy steel from the British Chemical Standard and several rock samples from the Geological Survey of Japan. The results were found to be in good agreement with the results determined by both wet chemical analysis and empirical coefficient analysis, and indicate that the FP method is a useful and convenient tool for the quantitative analysis of a multi-component mixture with a complicated chemical component.
\end{abstract}

\section{INTRODUCTION}

Chemical analysis by $\mathrm{X}$-ray spectrometry (XRF) with a classical high power sealed $\mathrm{X}$-ray tube requires only a simple and quick operation and is known to be one of the powerful tools for determining the chemical composition of various materials.

The XRF technique is based on the fact that any element emits a characteristic line spectrum when subjected to appropriate excitation of high energy by $\mathrm{X}$-rays or accelerated particles and that such

\footnotetext{
IOn leave from Precious Minerals Marketing Corporation, Ghana
}

fluorescent radiations are analyzed in order to obtain information on elements and their amounts in the sample. The intensity, $I_{i}$, of a fluorescent line from element $i$ would be proportional to the atomic fraction of $W_{i}$ in the sample. Then, the sample composition can be determined by comparing the intensity for a desired element with that of a similar sample with a known chemical composition. However, it is known that radiations emitted from other coexisting elements frequently make the determination very difficult, due to variations in matrix absorption and enhancement. The use of the fundamental parameter (FP) method without making calibration curves brings about a significant breakthrough in such problems of co-existing elements $/ 1 /$.

The purpose of this work is to test the FP method for quantitative $\mathrm{X}$-ray fluorescent analysis of a multicomponent inorganic system.

\section{PRINCIPLE OF FP METHOD}

Measured fluorescent intensity for an element should not be proportional to its amount due to the absorption effect of the sample and the enhancement by other elements. This feature requires the determination of so-called calibration curves including the matrix effects arising from the coexisting elements. The FP method permits 
determination of the composition of a sample directly from the measured intensity by using a few fundamental parameters of the primary spectral distribution from the $\mathrm{X}$-ray tube, absorption coefficient and fluorescent yield of elements in the sample coupled with a mathematical procedure. Figure 1 presents a FP method flow chart. The following conditions are included in this process:

1. assuming an approximate chemical composition, $W^{(0)}$, for the unknown sample using the sensitivity factor of each facility determined in advance;

2. calculating the theoretical intensities of fluorescent radiation using the basic equations;

3. comparing the measured intensity data with the theoretical one; and

4. estimating the composition, $W^{(n)}$, so as to coincide with the measured intensity by the $n$-times iterations.

The intensities of theoretical fluorescent radiation can be expressed by the following equations $/ 1,2 /$ :

$I_{i}=I_{i}^{n}+\bar{I}_{i}^{S}$

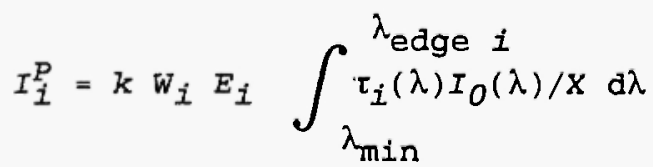

$I_{i}^{S}=0.5 k W_{i} E_{i} \quad \sum w_{j} E_{j}$

$\int_{\lambda_{\min }}^{\lambda_{\text {edge } j}(\lambda) \tau_{i}\left(\lambda_{j}\right) I_{o}(\lambda) Y / X d \lambda}$

$E_{i}=(\gamma-1.0) / \gamma \omega g$

$X=\mu(\lambda) / \sin \varphi_{I}+\mu\left(\lambda_{i}\right) / \sin \varphi_{2}$

$Y=\ln \left(1.0+\mu(\lambda) / \mu\left(\lambda_{j}\right) \sin \varphi_{I}\right) \sin \varphi_{I} / \mu(\lambda)$

$+\ln \left(1.0+\mu\left(\lambda_{i}\right) / \mu\left(\lambda_{f}\right) \sin \varphi_{2}\right) \sin \varphi_{2} / \mu\left(\lambda_{i}\right)$
$\mu(\lambda)=\Sigma w_{f}(\mu / \rho)_{j}(\lambda)$

where

i,j $\quad:$ elements

$I^{P} \quad$ : intensity of primary fluorescence,

$I^{S} \quad:$ intensity of secondary fluorescence,

$\lambda \quad:$ wave length,

$I_{O} \quad$ : primary X-ray spectrum,

$\lambda_{\text {edge } i}:$ wave length of absorption edge for element-i,

$\tau$ : mass photoelectric absorption coefficient,

$\mu / \mathrm{p} \quad:$ mass absorption coefficient,

$(\gamma-1.0) / \gamma:$ the probability of $K, L$ or $M$ excitation,

$g \quad:$ the transition probability,

$\omega \quad$ : fluorescence yield,

$\lambda_{m i n} \quad$ : short wave length limit of the spectral distribution,

$\varphi_{1}, \varphi_{2}$ : incident and emergence angles,

$k$ : sensitivity factor, and

$W \quad$ : concentration.

\section{EXPERIMENTALS}

The present XRF analysis was done on the socalled wavelength-dispersive mode of a $3270 \mathrm{E}$ system (RIGAKU Co. Ltd.) including a sealed X-ray tube of rhodium target (OEG-75H Rh) usually operated at 50 $\mathrm{kV}$ and $50 \mathrm{~mA}$, six analyzing crystals of $\mathrm{LiF}, \mathrm{Ge}, \mathrm{PET}$, TAP, RX40, RX60 and the X-ray counting devices of a scintillation counter and a gas-flow proportional counter. Fig. 2 presents the schematic diagram of the present X-ray fluorescent spectroscopic apparatus. The use of these combinations covers energy analysis for light elements such as $B$ and $C$ and heavy elements like $U$ without changing an $X$-ray tube. Such convenience is readily understood from the schematic drawing of Fig. 3. The best selection of the experimental combinations was automatically made by computer. The following points considering the $2 \theta$ positions of a monochromator and the corresponding values of a pulse height analyzer (PHA) for the intensity measurement may be noteworthy.

Fig. 4a shows the intensity profile of a rock sample using the results of characteristic line measured by a 


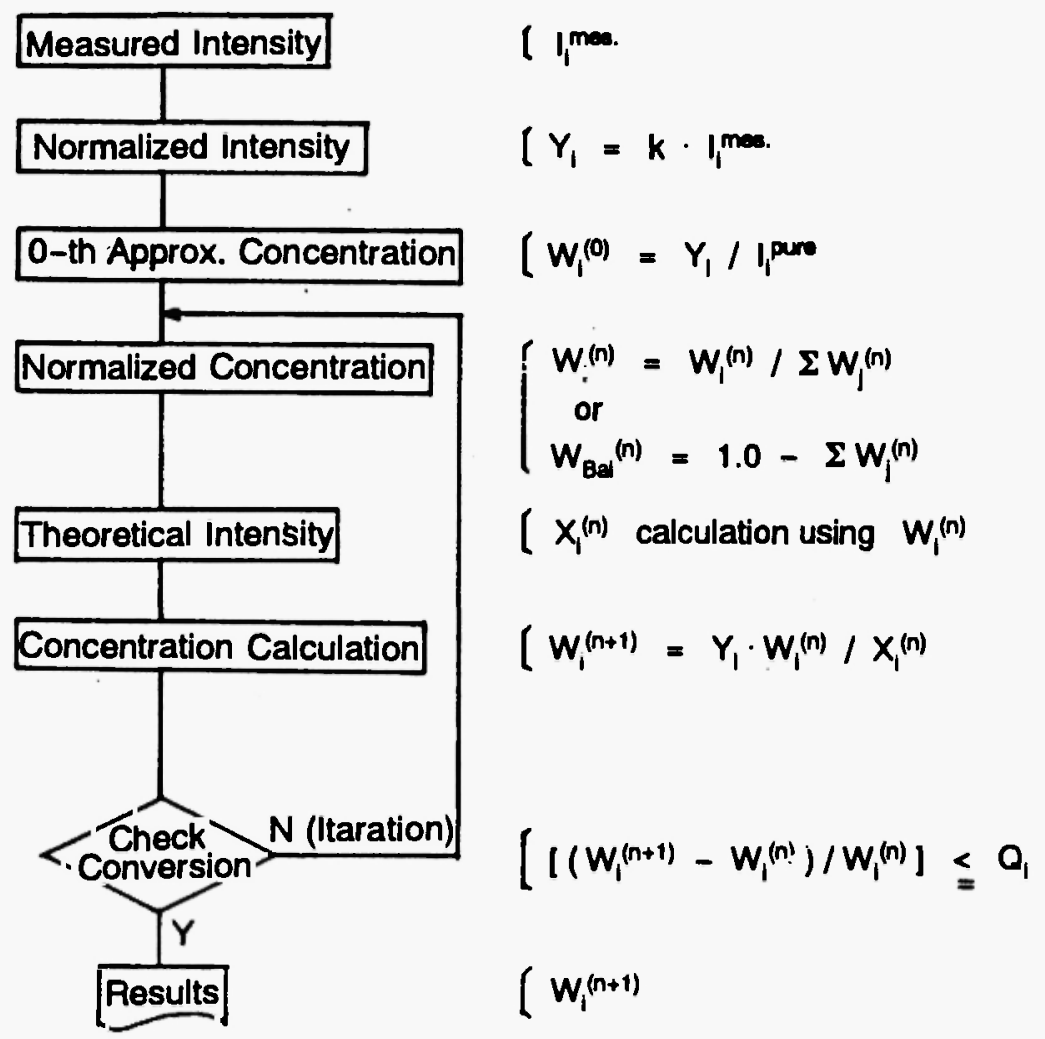

Fig. 1: Flow chart of the calculating sequence in the fundamental parameter (FP) method.

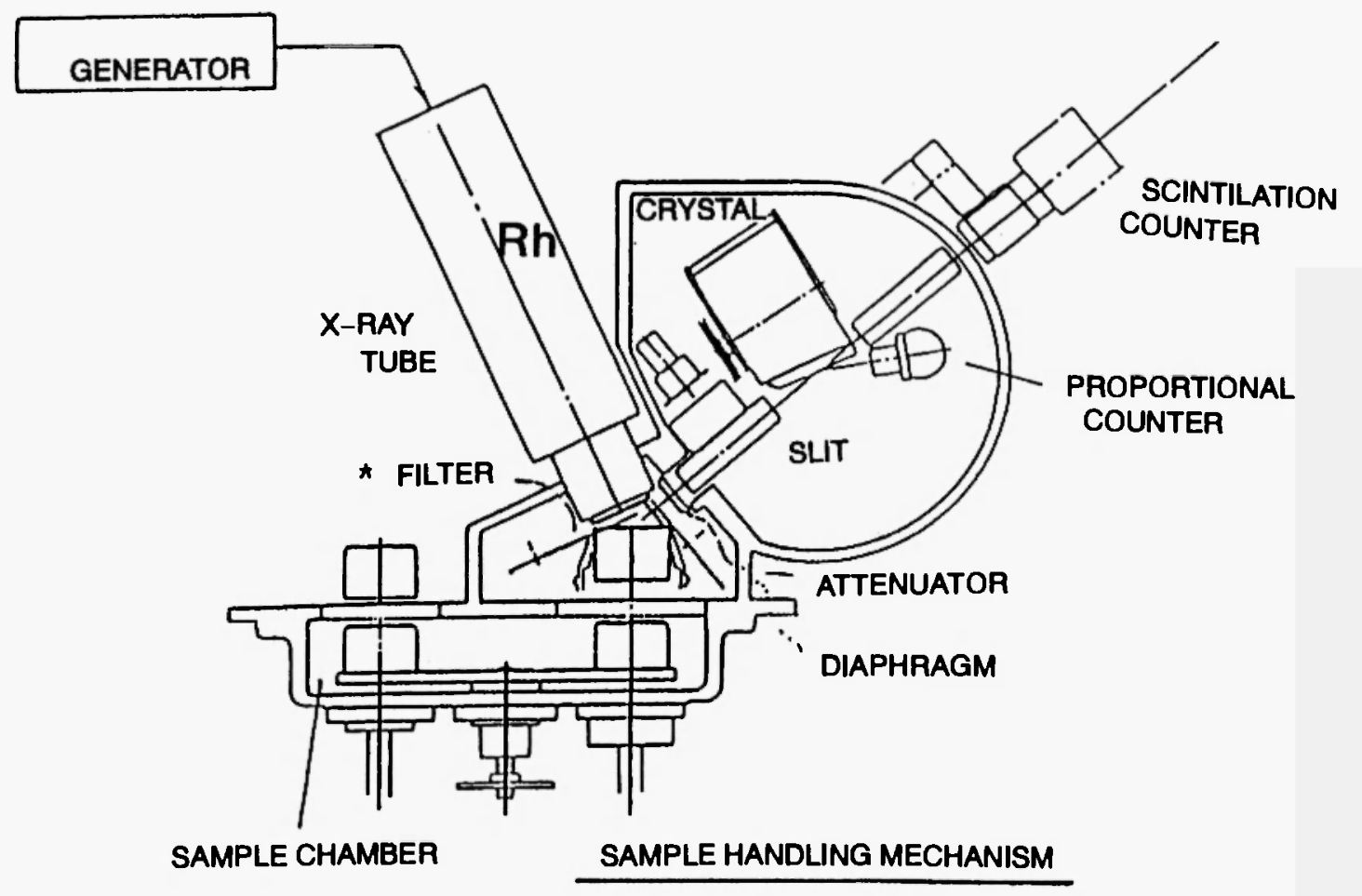

Fig. 2: Schematic diagram of the $\mathrm{X}$-ray fluorescent spectrometer used. 


\section{$X$-RAY TUBE}

\begin{tabular}{|c|c|}
\hline Ah & 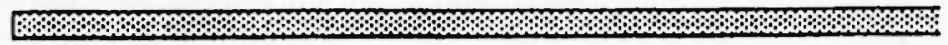 \\
\hline $\mathrm{Cr}$ &  \\
\hline W/Mo &  \\
\hline
\end{tabular}

\section{CAYSTAL}

\begin{tabular}{|c|c|}
\hline LF (200) &  \\
\hline LiF (220) & $\checkmark$ \\
\hline EDDT/PET & A) \\
\hline Ge & $P$ \\
\hline TAP & 0 \\
\hline$R X, A D P$ & B \\
\hline
\end{tabular}

COUNTER



Fig. 3: Various $\mathrm{X}$-ray tubes, monochromator crystals and counters for $\mathrm{X}$-rays, which are commonly used in $\mathrm{X}$-ray fluorescent analysis.

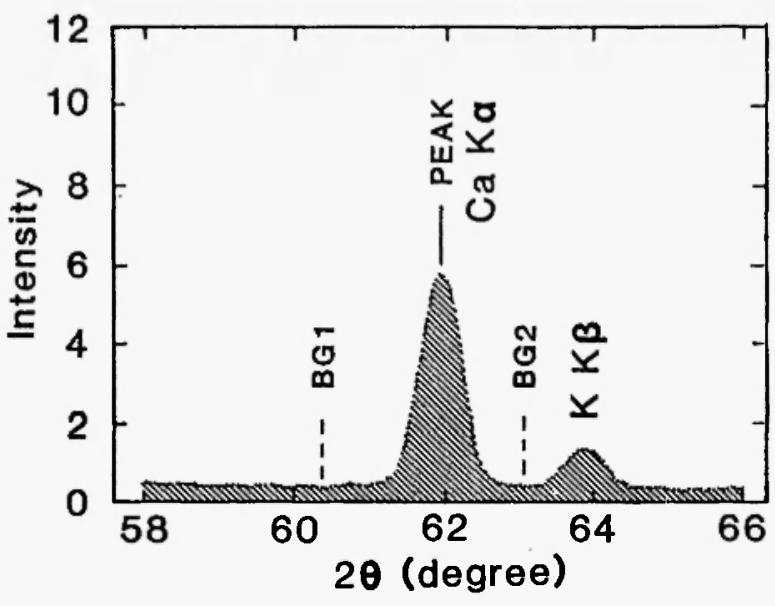

Fig. 4a: $\quad \mathrm{Ca} K \alpha$ and $\mathrm{K} K \boldsymbol{\beta}$ characteristic line spectra produced from a glass bead sample of granite analyzed by $\mathrm{Ge}$ monochromator with the pulse height analyzer.

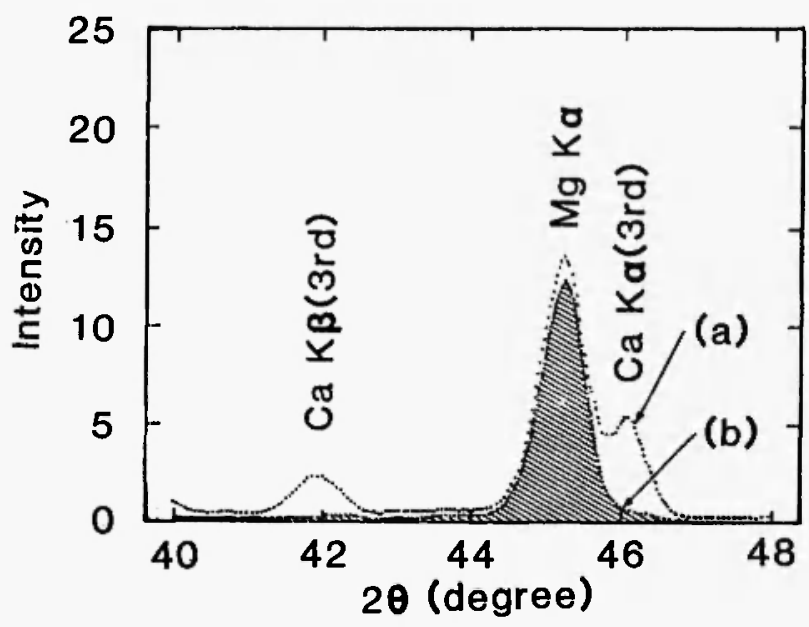

Fig. 4b: $\quad \mathrm{Mg} K \alpha$ and $\mathrm{Ca} K \alpha$ (3rd) characteristic line spectra produced from an iron-making slag sample (a) without pulse height analyzer and (b) with pulse height analyzer. 
Ge crystal, as an example. Some rock samples are known to include both calcium and potassium; then the $\mathrm{K} K \beta$ line interferes more or less in the background measurements on the higher angle side of the $\mathrm{Ca} K \alpha$ line. Such a factor should be carefully considered in determining the experimental conditions. The intensity profile of an iron-making slag sample is illustrated in Fig. 4b, using the results of the $\mathrm{Mg}-\mathrm{K} \alpha$ characteristic line measured by a PET crystal and a proportional counter. Usually an ironmaking slag sample includes a large amount of calcium and then $\mathrm{CaK} \alpha$ line is superimposed on the angular region of $\mathrm{Mg} K \alpha$ line. As can be easily seen from the results in Fig. 4b, the use of a PHA appears to reduce such difficulty by removing the intensity profile attributed to the $\mathrm{Ca} K \alpha$ line and thus enabling us to obtain sufficiently accurate information on the $\mathrm{Mg} K \boldsymbol{\alpha}$ line alone.

Details of the sample preparation and analytical conditions follow.

\subsection{Low Alloy Steels}

Usually metallic samples in chip or powder form are remelted for casting in order to make a disc shape. The present study used eight low alloy steel samples in disc form certified by the Bureau of Analysed Samples, Ltd., the surfaces of which were polished to a mirror finish with a $3 \mu \mathrm{m}$ alumina suspension on a cloth wheel. Four of them were used in order to determine the senistivity factor for each element of $\mathrm{Si}$, $\mathrm{Mn}, \mathrm{Ni}, \mathrm{Cr}, \mathrm{Mo}, \mathrm{V}$, and $\mathrm{Cu}$. The instrumental parameters for the measurement of fluorescent intensity are summarized in Table 1 . It may be added that the contents of $\mathrm{Fe}$ in these samples are over 95 mass \% and are regarded as the balance element in the present analysis.

\subsection{Igneous Rocks}

As for the rock samples certified by the Geological Survey of Japan $13 /$, the glass-transformed solid solution technique (the so-called glass-bead technique) for producing a glass disc with a smooth surface was applied with lithium tetraborate as a flux to reduce the matrix effect and homogenize the samples $/ 1 \%$. Some of the samples were used to determine sensitivity factors for the respective components. The experimental condition for each fluorescent radiation is given in Table 2 .

\section{RESULTS AND DISCUSSION}

The results for low-alloy steel samples are shown in Table 3 together with the reference values certified by analysis after standardization of Great Britain. This clearly indicates that the FP method is a useful tool for the quantitative analysis of a multi-component

\section{TABLE 1}

Instrumental Parameters for the Chemical Analysis of Low Alloy Steels of the British Chemical Standards

\begin{tabular}{|c|c|c|c|c|c|c|}
\hline \multirow{3}{*}{ Element } & \multirow{3}{*}{$\begin{array}{l}\text { Analyzing } \\
\text { crystal }\end{array}$} & \multirow{3}{*}{ Counter } & \multicolumn{3}{|c|}{$2 \theta$ (degree) } & \multirow{3}{*}{$\begin{array}{l}\text { Pulse Height } \\
\text { Analyzer } \\
\text { (PHA) }\end{array}$} \\
\hline & & & \multirow[t]{2}{*}{ Peak } & \multicolumn{2}{|c|}{ Background } & \\
\hline & & & & (1) & (2) & \\
\hline Si & PET & PC & 109.000 & 106.000 & 112.000 & $100-300$ \\
\hline Mn & LiF & SC & 63.000 & 61.780 & 63.780 & $100-300$ \\
\hline Mo & LiF & $\mathrm{SC}$ & 20.350 & 19.790 & 21.020 & $100-300$ \\
\hline V & LiF & SC & 76.910 & 76.310 & 77.510 & $100-300$ \\
\hline $\mathrm{Cu}$ & LiF & $\mathrm{SC}$ & 45.010 & 44.410 & 45.610 & $100-300$ \\
\hline $\mathrm{Cr}$ & $\mathrm{LiF}$ & SC & 69.380 & 68.780 & 69.980 & $100-300$ \\
\hline $\mathrm{Ni}$ & $\mathrm{LiF}$ & $\mathrm{SC}$ & 48.650 & 48.050 & 49.250 & $100-300$ \\
\hline
\end{tabular}


mixture by obtaining a good agreement with the reference values.

As for the silicate rock samples, the results are compared with the reference values $/ 3$ / and the values determined by using the common empirical coefficient method with the correction matrix of the Lachance-Traill algorithm, see Table 4. It is worth mentioning that the results in Table 4 are normalized so that the total amount of the elements is 100 mass\%. The difference of about \pm 0.2 mass $\%$ appears to be in the contents of $\mathrm{SiO}_{2}$ and $\mathrm{Al}_{2} \mathrm{O}_{3}$. However, it is stressed that the present FP method results again are in good agreement with the reference values and indicate no significant inconsistency with the results determined by empirical coefficient analysis. Thus, the present authors hold the view that the FP method is a useful and powerful analytical technique for a multicomponent mixture with complicated chemical composition, especially when not enough references samples can be prepared to determine the various empirical coefficients.

\section{ACKNOWLEDGEMENTS}

The authors thank S. Itoh of the Geological Survey

\section{TABLE 2}

Analysis of Low Alloy Steel Standards by the Fundamental Parameter (FP) Method together with Reference Values

\begin{tabular}{llcccccccc}
\hline & & \multicolumn{10}{c}{ Composition (mass 8 ) } \\
BSC.NO. & Method & $\mathrm{Si}$ & $\mathrm{Mn}$ & $\mathrm{Ni}$ & $\mathrm{Cr}$ & $\mathrm{Mo}$ & $\mathrm{V}$ & $\mathrm{Cu}$ & $\mathrm{Fe}$ \\
\hline \multirow{2}{*}{$252 / 1$} & reference & 0.28 & 0.34 & 2.23 & 0.42 & 1.05 & 0.23 & 0.20 & $\mathrm{bal}$ \\
& fundamental & 0.29 & 0.34 & 2.26 & 0.43 & 1.09 & 0.22 & 0.20 & $\mathrm{bal}$ \\
\multirow{2}{*}{$253 / 1$} & reference & 0.65 & 0.84 & 1.00 & 0.99 & 0.67 & 0.51 & 0.39 & $\mathrm{bal}$ \\
& fundamental & 0.63 & 0.83 & 1.00 & 1.01 & 0.67 & 0.51 & 0.39 & $\mathrm{bal}$ \\
$254 / 1$ & reference & 0.22 & 0.26 & 3.26 & 0.27 & 0.23 & 0.15 & 0.34 & $\mathrm{bal}$ \\
& fundamental & 0.20 & 0.30 & 3.36 & 0.28 & 0.23 & 0.15 & 0.35 & $\mathrm{bal}$ \\
$256 / 1$ & reference & 0.23 & 1.02 & 0.19 & 2.33 & 0.53 & 0.18 & 0.16 & $\mathrm{bal}$ \\
& fundamental & 0.22 & 1.03 & 0.19 & 2.36 & 0.54 & 0.18 & 0.17 & $\mathrm{bal}$ \\
\hline
\end{tabular}

TABLE 3

Instrumental Parameters for the Chemical Analysis of Rock Standards of the Geological Survey of Japan

\begin{tabular}{|c|c|c|c|c|c|c|}
\hline \multirow{3}{*}{ Element } & \multirow{3}{*}{$\begin{array}{c}\text { Analyzing } \\
\text { crystal }\end{array}$} & \multirow{3}{*}{ Counter } & \multicolumn{3}{|c|}{$2 \theta$ (degree) } & \multirow{3}{*}{$\begin{array}{l}\text { Pulse Height } \\
\text { Analyzer } \\
\text { (PHA) }\end{array}$} \\
\hline & & & \multirow[t]{2}{*}{ Peak } & \multicolumn{2}{|c|}{ Background } & \\
\hline & & & & (1) & (2) & \\
\hline $\mathrm{SiO}_{2}$ & PET & PC & 109.080 & 106.040 & 112.040 & $100-300$ \\
\hline $\mathrm{TiO}_{2}^{2}$ & LiF & SC & 86.180 & 85.220 & 86.710 & $100-300$ \\
\hline $\mathrm{Al}_{2} \mathrm{O}_{3}$ & PET & PC & 144.780 & 140.000 & 147.000 & $100-300$ \\
\hline $\mathrm{Fe}_{2} \mathrm{U}_{3}$ & LiF & SC & 57.540 & 56.060 & 59.300 & $100-300$ \\
\hline MnO & $\mathrm{LiF}$ & SC & 63.000 & 61.780 & 63.780 & $100-300$ \\
\hline MgO & TAP & PC & 45.225 & 43.125 & 47.275 & $130-265$ \\
\hline CaO & LiF & PC & 61.950 & 60.600 & 63.100 & $100-300$ \\
\hline $\mathrm{Na}_{2} \mathrm{O}$ & TAP & PC & 55.200 & 53.200 & 57.200 & $100-300$ \\
\hline $\mathrm{K}, \mathrm{O}$ & $\mathrm{Ge}$ & $\mathrm{PC}$ & 69.950 & 67.375 & 72.125 & $100-300$ \\
\hline $\mathrm{P}_{2} \mathrm{O}_{5}$ & $\mathrm{Ge}$ & PC & 141.050 & 139.100 & 143.325 & $100-300$ \\
\hline
\end{tabular}




\section{TABLE 4}

Analysis of Igneous Rock Samples of the Geological Survey of Japan by the Empirical Coefficients Method and the Fundamental Parameter (FP) Method together with the Reference Values /3/

\begin{tabular}{|c|c|c|c|c|c|c|c|c|c|c|c|}
\hline \multirow[b]{2}{*}{ Sample } & \multirow[b]{2}{*}{ Method } & \multicolumn{9}{|c|}{ Composition (mass $q$ ) } & \multirow[b]{2}{*}{$\mathrm{P}_{2} \mathrm{O}_{5}$} \\
\hline & & $\mathrm{SiO}_{2}$ & $\mathrm{TiO}_{2}$ & $\mathrm{Al}_{2} \mathrm{O}_{3}$ & $\mathrm{Fe}_{2} \mathrm{O}_{3}$ & Mno & MgO & $\mathrm{CaO}$ & $\mathrm{Na}_{2} \mathrm{O}$ & $\mathrm{K}_{2} \mathrm{O}$ & \\
\hline$J A-2$ & $\begin{array}{l}\text { reference } \\
\text { empirical } \\
\text { fundamental }\end{array}$ & $\begin{array}{l}57.55 \\
57.53 \\
57.46\end{array}$ & $\begin{array}{l}0.69 \\
0.68 \\
0.69\end{array}$ & $\begin{array}{l}15.68 \\
15.76 \\
15.71\end{array}$ & $\begin{array}{l}6.29 \\
6.51 \\
6.44\end{array}$ & $\begin{array}{l}0.11 \\
0.11 \\
0.10\end{array}$ & $\begin{array}{l}7.86 \\
7.69 \\
7.86\end{array}$ & $\begin{array}{l}6.63 \\
6.55 \\
6.53\end{array}$ & $\begin{array}{l}3.15 \\
3.22 \\
3.24\end{array}$ & $\begin{array}{l}1.84 \\
1.79 \\
1.82\end{array}$ & $\begin{array}{l}0.15 \\
0.16 \\
0.15\end{array}$ \\
\hline JA-3 & $\begin{array}{l}\text { reference } \\
\text { empirical } \\
\text { fundamental }\end{array}$ & $\begin{array}{l}62.37 \\
62.14 \\
62.15\end{array}$ & $\begin{array}{l}0.68 \\
0.68 \\
0.69\end{array}$ & $\begin{array}{l}15.60 \\
15.62 \\
15.61\end{array}$ & $\begin{array}{l}6.60 \\
6.58 \\
6.58\end{array}$ & $\begin{array}{l}0.11 \\
0.10 \\
0.10\end{array}$ & $\begin{array}{l}3.66 \\
3.63 \\
3.74\end{array}$ & $\begin{array}{l}6.29 \\
6.38 \\
6.38\end{array}$ & $\begin{array}{l}3.18 \\
3.34 \\
3.25\end{array}$ & $\begin{array}{l}1.41 \\
1.40 \\
1.40\end{array}$ & $\begin{array}{l}0.11 \\
0.11 \\
0.11\end{array}$ \\
\hline JF -1 & $\begin{array}{l}\text { reference } \\
\text { empirical } \\
\text { fundamental }\end{array}$ & $\begin{array}{l}67.14 \\
67.31 \\
67.34\end{array}$ & $\begin{array}{l}0.00 \\
0.00 \\
0.00\end{array}$ & $\begin{array}{l}18.12 \\
18.17 \\
18.20\end{array}$ & $\begin{array}{l}0.08 \\
0.12 \\
0.09\end{array}$ & $\begin{array}{l}0.00 \\
0.00 \\
0.00\end{array}$ & $\begin{array}{l}0.01 \\
0.03 \\
0.00\end{array}$ & $\begin{array}{l}0.93 \\
0.92 \\
0.93\end{array}$ & $\begin{array}{l}3.57 \\
3.41 \\
3.38\end{array}$ & $\begin{array}{l}10.14 \\
10.03 \\
10.05\end{array}$ & $\begin{array}{l}0.01 \\
0.02 \\
0.01\end{array}$ \\
\hline JG-1a & $\begin{array}{l}\text { reference } \\
\text { empirical } \\
\text { fundamental }\end{array}$ & $\begin{array}{l}72.85 \\
72.81 \\
72.88\end{array}$ & $\begin{array}{l}0.25 \\
0.24 \\
0.25\end{array}$ & $\begin{array}{l}14.35 \\
14.28 \\
14.26\end{array}$ & $\begin{array}{l}2.07 \\
2.06 \\
2.04\end{array}$ & $\begin{array}{l}0.06 \\
0.06 \\
0.06\end{array}$ & $\begin{array}{l}0.70 \\
0.70 \\
0.70\end{array}$ & $\begin{array}{l}2.15 \\
2.19 \\
2.19\end{array}$ & $\begin{array}{l}3.44 \\
3.51 \\
3.48\end{array}$ & $\begin{array}{l}4.05 \\
4.06 \\
4.07\end{array}$ & $\begin{array}{l}0.08 \\
0.09 \\
0.08\end{array}$ \\
\hline JG-3 & $\begin{array}{l}\text { reference } \\
\text { empirical } \\
\text { fundamental }\end{array}$ & $\begin{array}{l}67.62 \\
67.66 \\
67.73\end{array}$ & $\begin{array}{l}0.48 \\
0.47 \\
0.48\end{array}$ & $\begin{array}{l}15.64 \\
15.52 \\
15.52\end{array}$ & $\begin{array}{l}3.76 \\
3.73 \\
3.72\end{array}$ & $\begin{array}{l}0.07 \\
0.07 \\
0.07\end{array}$ & $\begin{array}{l}1.80 \\
1.78 \\
1.80\end{array}$ & $\begin{array}{l}3.79 \\
3.82 \\
3.83\end{array}$ & $\begin{array}{l}4.06 \\
4.17 \\
4.10\end{array}$ & $\begin{array}{l}2.65 \\
2.64 \\
2.64\end{array}$ & $\begin{array}{l}0.12 \\
0.14 \\
0.13\end{array}$ \\
\hline$J R-2$ & $\begin{array}{l}\text { reference } \\
\text { empirical } \\
\text { fundamental }\end{array}$ & $\begin{array}{l}76.78 \\
76.82 \\
76.93\end{array}$ & $\begin{array}{l}0.09 \\
0.06 \\
0.06\end{array}$ & $\begin{array}{l}13.01 \\
12.93 \\
12.89\end{array}$ & $\begin{array}{l}0.87 \\
0.79 \\
0.77\end{array}$ & $\begin{array}{l}0.11 \\
0.11 \\
0.10\end{array}$ & $\begin{array}{l}0.05 \\
0.07 \\
0.05\end{array}$ & $\begin{array}{l}0.46 \\
0.53 \\
0.53\end{array}$ & $\begin{array}{l}4.09 \\
4.08 \\
4.05\end{array}$ & $\begin{array}{l}4.51 \\
4.59 \\
4.60\end{array}$ & $\begin{array}{l}0.01 \\
0.01 \\
0.01\end{array}$ \\
\hline JR-3 & $\begin{array}{l}\text { reference } \\
\text { empirical } \\
\text { fundamental }\end{array}$ & $\begin{array}{l}73.37 \\
73.33 \\
73.48\end{array}$ & $\begin{array}{l}0.21 \\
0.22 \\
0.22\end{array}$ & $\begin{array}{l}12.25 \\
12.16 \\
12.12\end{array}$ & $\begin{array}{l}4.81 \\
4.78 \\
4.77\end{array}$ & $\begin{array}{l}0.09 \\
0.08 \\
0.08\end{array}$ & $\begin{array}{l}0.05 \\
0.06 \\
0.04\end{array}$ & $\begin{array}{l}0.09 \\
0.10 \\
0.10\end{array}$ & $\begin{array}{l}4.74 \\
4.89 \\
4.81\end{array}$ & $\begin{array}{l}4.38 \\
4.36 \\
4.38\end{array}$ & $\begin{array}{l}0.01 \\
0.02 \\
0.01\end{array}$ \\
\hline
\end{tabular}

of Japan for supplying rock standards. The technical advice of H. Fujimaki, Faculty of Science, Tohoku University is also greatly appreciated.

\section{REFERENCES}

1. (e.g.) Tertian, R. and Claisse, F., Principles of
Quantitative X-ray Fluorescence Analysis, Heyden \& Son Ltd., London (1982).

2. Rigaku Ind. Corp., X-ray Spectrometer SYSTEM 3270 Operation Manual.

3. Ando, A., Kamioka, H., Terashima, S. and Itoh, S., Geochemical J., 23, 143 (1989). 
. 